\title{
Clinical outcomes of rare hepatocellular carcinoma variants compared to pure hepatocellular carcinoma
}

This article was published in the following Dove Press journal:

Journal of Hepatocellular Carcinoma

\author{
Katerina Zakka' \\ Renjian Jiang ${ }^{2}$ \\ Olatunji B Alese' \\ Walid L Shaib' \\ Christina $\mathrm{Wu}^{\prime}$ \\ Joel P Wedd ${ }^{3}$ \\ Marty T Sellers ${ }^{4}$ \\ Madhusmita Behera ${ }^{1,2}$ \\ Bassel F El-Rayes' \\ Mehmet Akce' \\ 'Department of Hematology and Medical \\ Oncology, Winship Cancer Institute, \\ Emory University School of Medicine, \\ Atlanta, GA, USA; ${ }^{2}$ Department of \\ Research Informatics, Winship Cancer \\ Institute, Emory University School of \\ Medicine, Atlanta, GA, USA; ${ }^{3}$ Division of \\ Digestive Diseases, Department of \\ Medicine, Emory University School of \\ Medicine, Atlanta, GA, USA; ${ }^{4}$ Division of \\ General and GI Surgery, Department of \\ Surgery, Emory University School of \\ Medicine, Atlanta, GA, USA
}

Background: HCC variants are rare primary hepatic tumors. The aim of this study is to compare clinical characteristics and outcomes of HCC variants with pure HCC.

Methods: Patients diagnosed between 2004 and 2013 with ICD-O-3 8180/3 and 8170/3$8175 / 3$ were identified from the National Cancer Database. Univariate and multivariate survival analyses were conducted to analyze the association between histology and overall survival (OS).

Results: 80,280 patients were identified; pure HCC 78,461 (97.7\%), fibrolamellar (FLHCC) $310(0.4 \%)$, scirrhous $161(0.2 \%)$, spindle cell $72(0.1 \%)$, clear cell $487(0.6 \%)$, pleomorphic $23(0.0 \%)$, and combined HCC and cholangiocarcinoma (mixed HCC) 766 (1.0\%). 76.7\% were male and $72 \%$ Caucasian. Liver transplant was performed in $10.1 \%$ of pure $\mathrm{HCC}$, $14.5 \%$ of mixed HCC, $16.2 \%$ of scirrhous, $6.9 \%$ of spindle cell, $8.8 \%$ of clear cell, $8.7 \%$ of pleomorphic, and $3.2 \%$ of FLHCC $(p<0.001)$. Pure HCC $(10.6 \%)$ underwent surgical resection without transplant less often than variants except for scirrhous $(9.9 \%)(p<0.001)$. More than a third of patients in each histological type received chemotherapy. FLHCC had the best 5 -year OS (38.7\%), spindle cell and pleomorphic had the worst $(9.6 \%$ and $13.0 \%)$. In multivariate analysis stratified by histology variants, chemotherapy was associated with improved OS in all histologies except for scirrhous and pleomorphic HCC.

Conclusion: HCC variants underwent surgical resection more often than pure HCC. FLHCC had the best 5-year OS. Liver transplant was commonly performed in HCC variants. Keywords: treatment, outcome, hepatocellular carcinoma, hepatocellular carcinoma variants

\section{Introduction}

Hepatocellular carcinoma (HCC) is the fourth leading cause of cancer-related mortality in the world. ${ }^{1}$ The incidence of HCC in the United States (US) is progressively rising making it the fastest growing cause of cancer-related mortality. HCC is currently the fifth leading cause of cancer death in males and the eighth leading cause of cancer death in females in the US. ${ }^{2}$ HCC typically arises in the setting of chronic liver inflammation and fibrosis. ${ }^{3}$ The prognosis of patients with $\mathrm{HCC}$ is poor, and 5-year survival rate of untreated $\mathrm{HCC}$ is only $12 \%{ }^{4}$ The best chance for long-term survival is by surgical resection, transplantation, or ablation of tumors. ${ }^{5,6}$ Unfortunately, these therapies apply to a small subset of patients with early stage disease. In addition, orthotopic liver transplantation (OLT) is limited by the availability of donor organs. ${ }^{7}$ The landscape of systemic treatment of advanced pure HCC has changed significantly in the recent
Department of Hematology and Medical Oncology, Winship Cancer Institute, Emory University School of Medicine, I 365 Clifton Road NE, Atlanta, GA 30322, USA

Tel + I 4047788025

$\mathrm{Fax}+1404686441$ I

Email mehmet.akce@emory.edu
Journal of Hepatocellular Carcinoma 2019:6 II9-129

119

DovePress $f y$ in $\boldsymbol{v}$

http://doi.org/10.2147यHc. 2215235 
years and currently single agent sorafenib and lenvatinib are approved for first line therapy; single agent regorafenib, nivolumab, cabozantinib and pembrolizumab are approved for second line therapy. ${ }^{8-13}$

A rare subset of patients present with primary hepatic tumors that have distinct pathologic features known as HCC variants. There are several HCC variants including but not limited to fibrolamellar, scirrhous, spindle cell, clear, pleomorphic and mixed HCC with cholangiocarcinoma. The clinical outcomes and treatment approaches of HCC variants are not as well characterized as pure HCC. Most studies have focused on understanding the clinicopathological features of fibrolamellar and scirrhous variants with minimal focus on the other subtypes. In addition to its unique pathologic feature, FLHCC is distinct from pure HCC clinically, arising in younger patients with a higher incidence in women, and usually without a background of chronic liver disease. ${ }^{14-16}$ Importantly, FLHCC has been demonstrated to have a better prognosis than pure $\mathrm{HCC}$, leading to significant interest in optimizing cure in this young and otherwise healthy patient population. ${ }^{14,15,17,18}$ On the other hand, scirrhous subtype was shown to have a more aggressive clinicopathological behavior compared to pure $\mathrm{HCC}$, with more infiltrative growth and vascular invasion. ${ }^{19}$ Clear cell variant usually shows similar clinical characteristics as pure $\mathrm{HCC} .{ }^{20} \mathrm{HCC}$ variants are rare and usually excluded from prospective trials. Hence there is no consensus on management. This study aimed to compare the clinical features, treatment modalities and outcomes of HCC variants to pure HCC in the National Cancer Database (NCDB).

\section{Patients and methods}

\section{Patient selection}

The NCDB is a national clinical cancer database collected from over 1,500 facilities that are accredited by the Commission on Cancer and represent $70 \%$ of newly diagnosed cancers in the US. The NCDB was queried with the following International Classification of Diseases for Oncology, third edition (ICD-O-3) morphological codes $8170 / 3-8175 / 3$ and $8180 / 3$, and topography code C22.0 in the participant user data file between years of 2004 and 2013.

\section{Eligibility criteria}

Eligible patients were defined as ages 18 till 89 years with stage I-IV pure HCC or HCC variant. The primary outcome was overall survival of patients with HCC in the different histology groups. Patient-specific covariates included age at diagnosis, gender, race, insurance status, year of diagnosis, primary site, AJCC analytic stage group, grade, histology, radiation, chemotherapy, surgery at primary site and surgical margins, amongst others (Table 1). Ethical approval was not required for the study since patient information in the database is completely de-identified and the database is legally accessible to the public.

\section{Statistical analysis}

The clinical and demographic characteristics of the patients were summarized using descriptive statistics as appropriate for variable type and distribution. Univariate and multivariate analyses were conducted to identify factors associated with patient outcome. To assess the association between patient characteristics and survival, Cox proportional hazards models were fitted with a backward elimination method (removal criteria $p=0.05$ ). Likelihood ratio test (LRT) was used to compare the model with the covariate being assessed; both added with the model and with the assessed covariate dropped. An alpha level of 0.05 was used, and any covariate with LRT $p$-value $>0.05$ was removed from the final multivariate model. We used backward elimination to automate the LRTs, and determine the final model with the covariates presented. Kaplan-Meier curves were generated to compare overall survival based on histological subtype. All analyses were done using SAS 9.4 (SAS Institute, Inc., Cary, North Carolina) and SAS macros developed by the Biostatistics and Bioinformatics Shared Resource at Winship Cancer Institute in Atlanta, Georgia. ${ }^{21}$

\section{Results}

\section{Patient demographics and tumor characteristics}

A total of 80,280 patients between 18 and 89 years of age were identified as detailed in the consort diagram (Figure 1). The majority of patients $(\mathrm{n}=78,461,97.7 \%)$ had pure HCC compared to variant subtypes where mixed histology $(\mathrm{n}=766$, $1.0 \%$ ) was the most common variant, followed by clear cell $(\mathrm{n}=487,0.6 \%)$, FLHCC $(\mathrm{n}=310,0.4 \%)$, scirrhous $(\mathrm{n}=161$, $0.2 \%)$, spindle cell $(\mathrm{n}=72,0.1 \%)$ and pleomorphic $(\mathrm{n}=23$, $0.0 \%)$. The mean age was 61.8 years ( $\mathrm{SD} \pm 10.9)$. The mean age at diagnosis was similar between all subtypes except for FLHCC which occurred at a much younger age (37.9 years vs $60.9-64.1$ years, $p<0.001)$. An overall male preponderance $(76.7 \%)$ was observed. This male preponderance was observed in all pure HCC patients and patients with HCC variants $(p<0.001)$. Caucasians and African Americans 


\begin{tabular}{|c|c|c|c|c|c|}
\hline$\frac{0}{\frac{0}{\pi}}$ & & $\begin{array}{l}\bar{\delta} \bar{o} \\
\dot{0} \\
\dot{0} \\
\dot{0}\end{array}$ & $\begin{array}{l}\overline{8} \\
\bar{v}\end{array}$ & 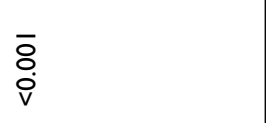 & 官 \\
\hline 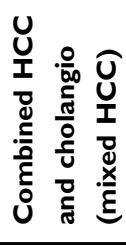 & $\stackrel{0}{\circ}$ & 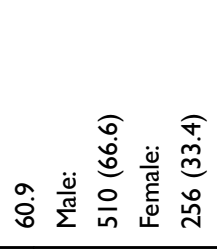 & 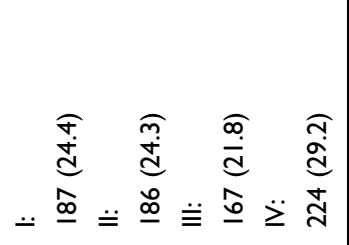 & 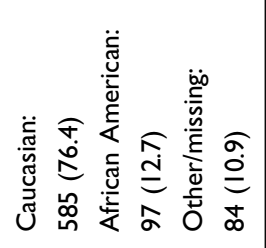 & 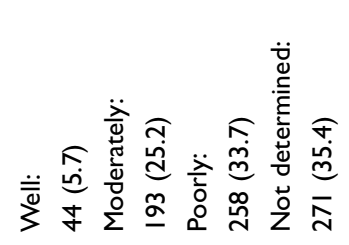 \\
\hline 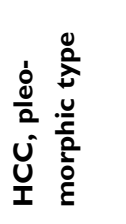 & ๗ $\stackrel{0}{\stackrel{0}{\varrho}}$ & 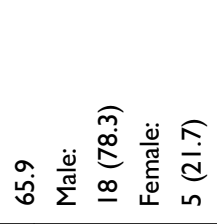 & 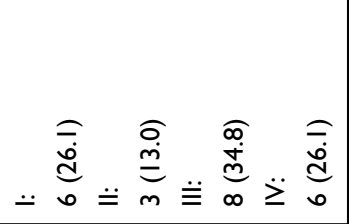 & 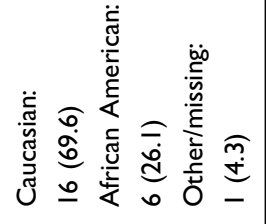 & 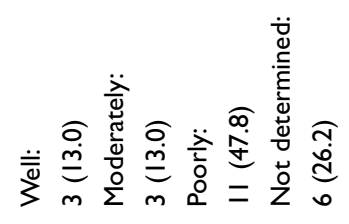 \\
\hline 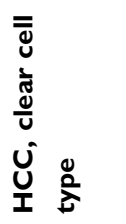 & कo & 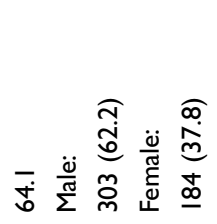 & 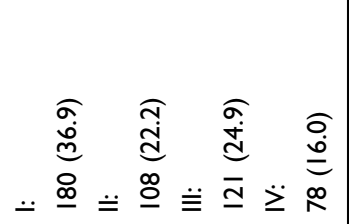 & 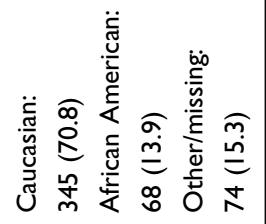 & 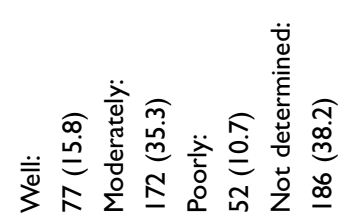 \\
\hline 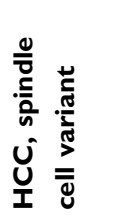 & $\therefore \widehat{\bar{e}}$ & 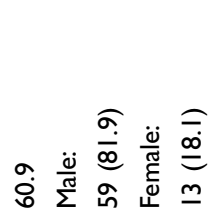 & 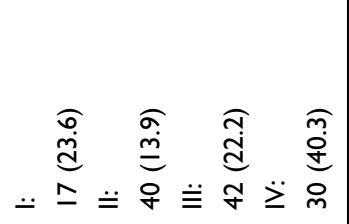 & 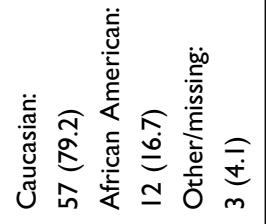 & 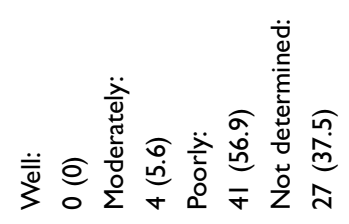 \\
\hline 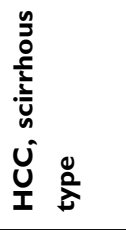 & ๘ & 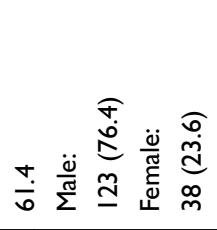 & 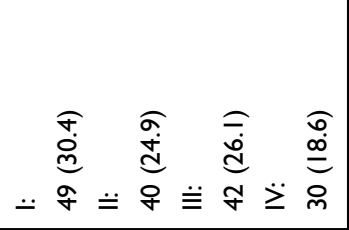 & 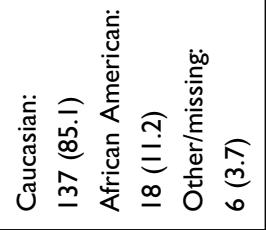 & 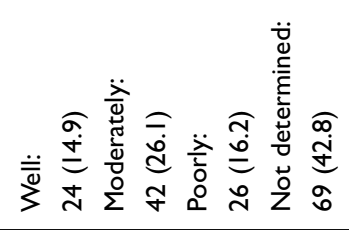 \\
\hline 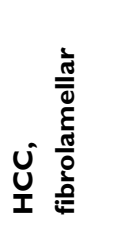 & 응 $\stackrel{\widehat{\sigma}}{\stackrel{5}{c}}$ & 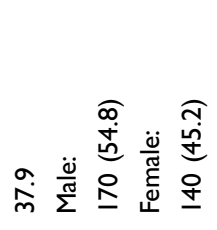 & 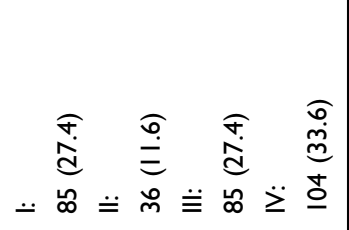 & 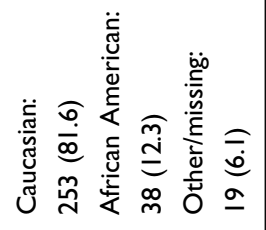 & 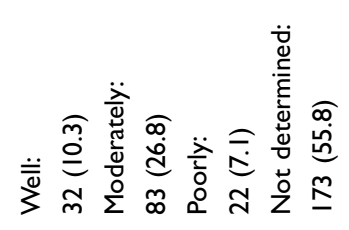 \\
\hline 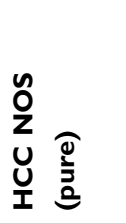 & 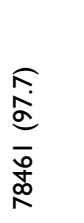 & 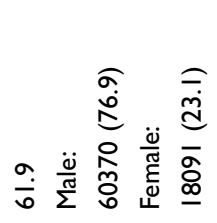 & 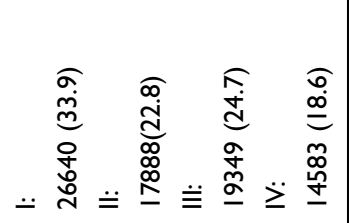 & 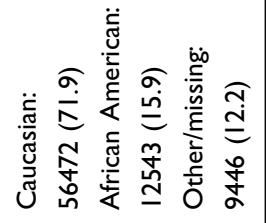 & 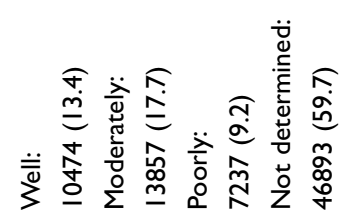 \\
\hline & 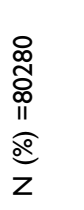 & 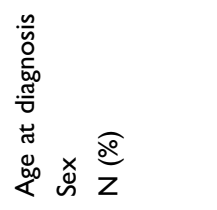 & 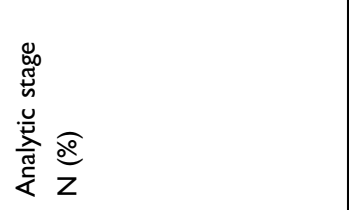 & 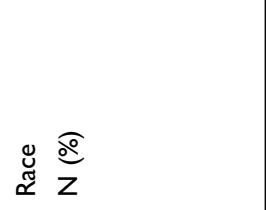 & 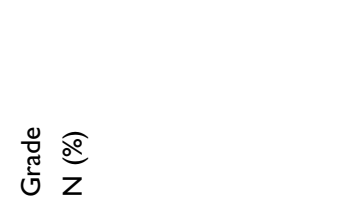 \\
\hline
\end{tabular}




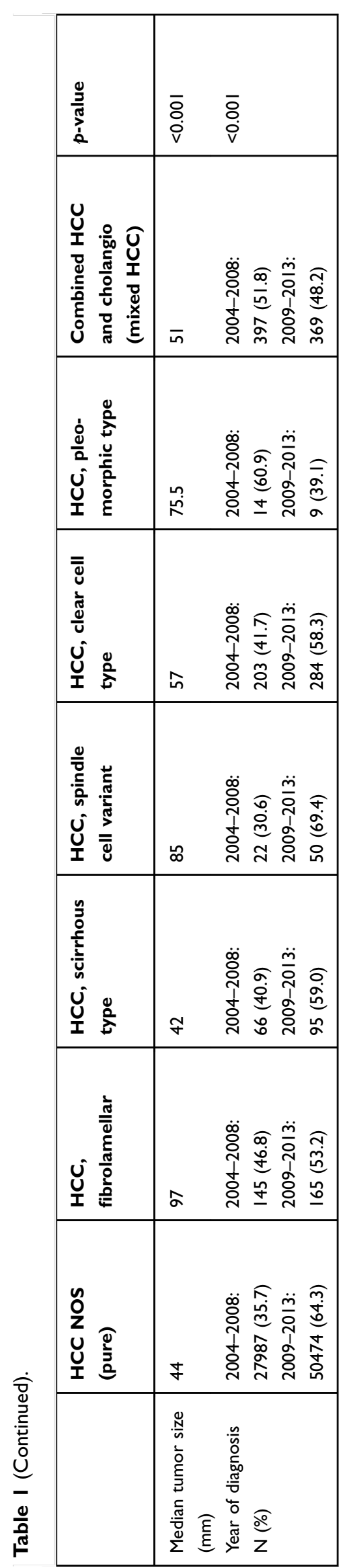

accounted for $72 \%$ and $15.9 \%$; respectively. Pure HCC and HCC variants occurred more commonly in Caucasians $(p<0.001)$. Distribution across stages I-IV was $33.9 \%$, $22.8 \%, 24.7 \%$ and $18.6 \%$ consecutively for pure HCC, and was significantly different among other histology groups (Table 1). One third of pure HCC (33.9\%), scirrhous (30.4\%), and clear cell (36.9\%) presented with stage I and one third of FLHCC (33.6\%) and mixed HCC (29.2\%) presented with stage IV disease. Spindle cell, pleomorphic, and mixed HCC subtypes were mostly poorly differentiated. Of all the tumors in the total cohort with a recorded size, the median tumor size was $44 \mathrm{~mm}$. FLHCC and spindle cell disease much more frequently presented as larger tumors with a median size of $97 \mathrm{~mm}$ and $85 \mathrm{~mm}$ respectively $(p<0.001)$. The percent of patients treated at community practices and academic or research cancer centers were $28.8 \%$ and $60.8 \%$ respectively. A higher number of patients were diagnosed between 2009 and 2013 for all patients, compared to 2004-2008 except for mixed HCC whereby 48.2\% were diagnosed between 2009 and $2013(p<0.001)$ (Table 1).

\section{Treatment modalities and outcomes Ablation, surgery without transplant and surgery with transplant}

Ablation procedure was performed in $9.8 \%$ of pure $\mathrm{HCC}$, and in up to $8.7 \%$ of $\mathrm{HCC}$ variants (Table 2). Compared to pure HCC (10.6\%), HCC variants were significantly more likely to undergo surgical resection without transplant except for scirrhous with rates of 54.8\% in FLHCC, 34.5\% in clear cell, $29.8 \%$ in mixed HCC, $33.3 \%$ in spindle cell, $34.8 \%$ in pleomorphic, and $9.9 \%$ in scirrhous $(p<0.001)$. Positive surgical margin rates were highest in tumors with the largest size including spindle cell variant $(9.7 \%, 85 \mathrm{~mm})$ and FLHCC $(6.8 \%, 97 \mathrm{~mm})$ compared to pure HCC $(1.9 \%, 44 \mathrm{~mm})$ $(p<0.001)$. Positive surgical margins on pathologic evaluation were associated with worse outcomes in both univariate and multivariate analysis (HR 2.60; 2.44-2.77; $p<0.001$ and HR $1.52 ; 1.42-1.62, p<0.001)$. Surgical resection treatment trends for all subtypes are shown in Table 2 . Surgical resection with liver transplantation was performed in $10.1 \%$ of pure HCC, $14.5 \%$ of mixed HCC, $16.2 \%$ of scirrhous, $6.9 \%$ of spindle cell, $8.8 \%$ of clear cell, $8.7 \%$ of pleomorphic, and $3.2 \%$ of FLHCC.

\section{Systemic therapy}

The role of systemic therapy is less established in HCC variants. The results of this study describe the national 


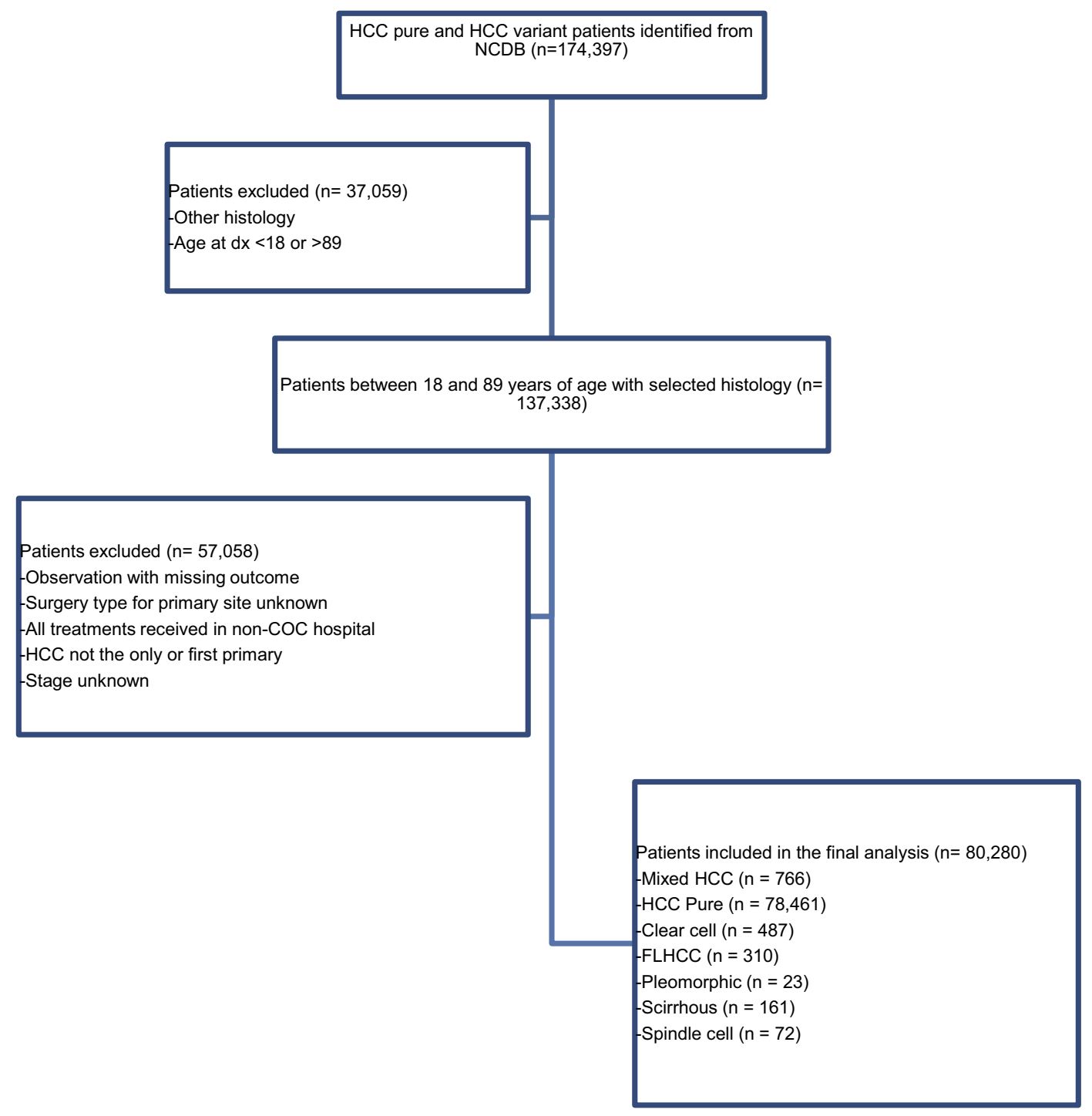

Figure I Consort diagram outlining the patient selection.

patterns of systemic therapy utilization in HCC variants; however, it lacks the details of the administered systemic therapy as the NCDB does not capture this information. Chemotherapy administration in different types were as following: pure HCC (42.3\%), FLHCC (41.3\%), mixed HCC (38.5\%), spindle cell (36.1\%), clear cell $(35.5 \%)$, pleomorphic (34.8\%), and scirrhous (31.1\%) $(p=0.005)$ (Table 2). Neoadjuvant systemic therapy was administered more in pleomorphic $(8.7 \%)$ and mixed HCC $(7.0 \%)$ compared to pure HCC $(5.8 \%)(p<0.001)$. Adjuvant systemic therapy was administered more often in FLHCC (8.1\%), spindle cell (9.7\%) and mixed HCC (7.4\%) compared to pure HCC $(2.2 \%)(p<0.001)$. In univariate analysis both neoadjuvant (HR $0.25 ; 0.24-0.26 ; p<0.001)$ and adjuvant (HR $0.60 ; 0.57-0.64 ; p<0.001)$ systemic therapy were associated with improved OS compared to no systemic therapy when the entire cohort is considered (Table 3). The prognostic advantage of chemotherapy for each HCC variant was not significant in univariate analysis and log-rank tests, which didn't adjust the potential confounding effects of other covariates. Such prognostic advantage became significant in multivariate analysis models. After controlling for potential confounders in multivariate analysis, chemotherapy was associated with improved OS in all histologies except for scirrhous and pleomorphic HCC (Table 4).

\section{Overall survival}

FLHCC had the best 5-year overall survival (OS). Clear cell, scirrhous, and pure HCC had similar 5-year OS followed by mixed HCC (Figure 2). Spindle cell and pleomorphic had the worst 5-year OS. In multivariate analysis, fibrolamellar histology (HR 0.77; 0.66-0.89; 


\begin{tabular}{|c|c|c|c|c|c|c|}
\hline 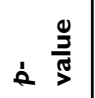 & $\begin{array}{l}\overline{8} \\
\dot{0} \\
v\end{array}$ & $\bar{o}$ & $\begin{array}{l}\stackrel{0}{0} \\
\stackrel{0}{0} \\
0\end{array}$ & 亗 & $\begin{array}{l}\overline{8} \\
\dot{0} \\
\mathrm{v}\end{array}$ & $\begin{array}{l}\overline{8} \\
\dot{0}\end{array}$ \\
\hline 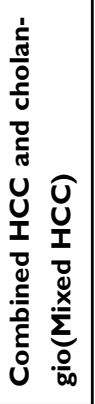 & 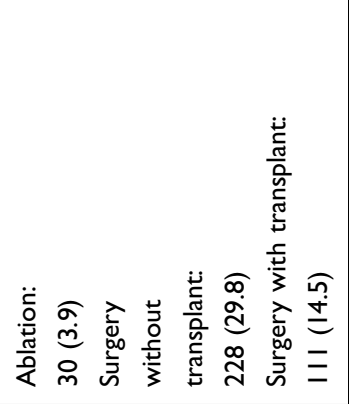 & 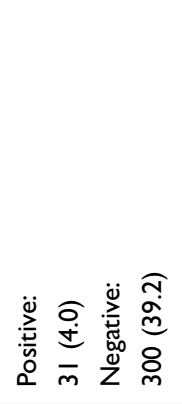 & 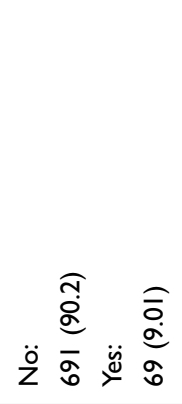 & 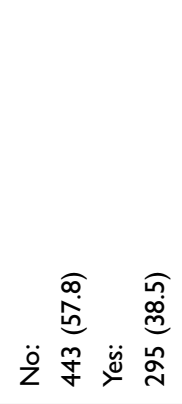 & $\underset{\bar{c}}{\stackrel{5}{5}}$ & $\begin{array}{l}\underset{5}{5} \\
\text { in }\end{array}$ \\
\hline 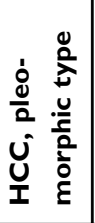 & 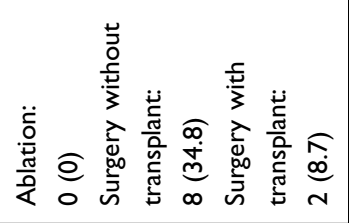 & 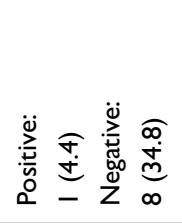 & 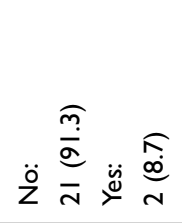 & 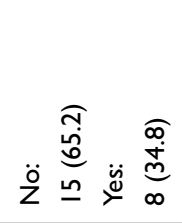 & $\underset{\sim}{\stackrel{\Gamma}{\infty}}$ & $\widehat{\widehat{c}}$ \\
\hline 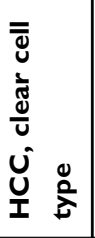 & 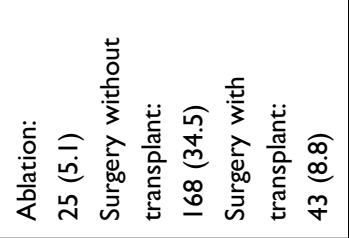 & 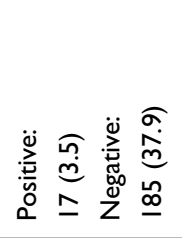 & 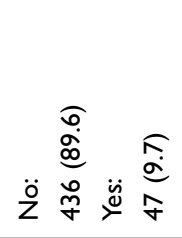 & 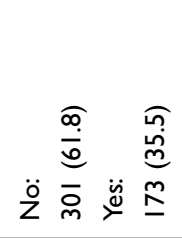 & 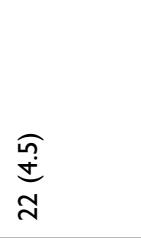 & $\begin{array}{l}\widehat{\tilde{m}} \\
\stackrel{c}{c} \\
\underline{0}\end{array}$ \\
\hline 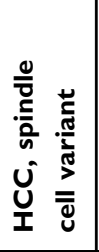 & 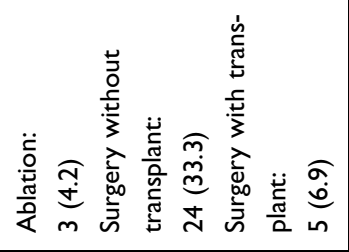 & 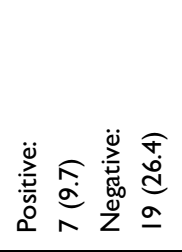 & 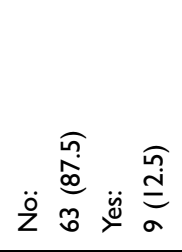 & 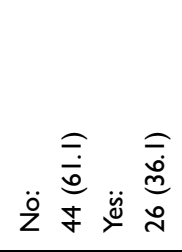 & 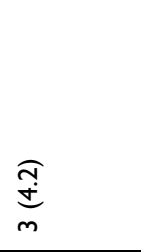 & 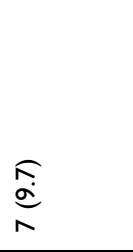 \\
\hline 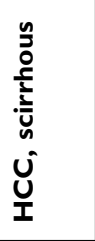 & 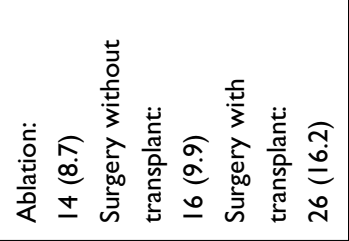 & 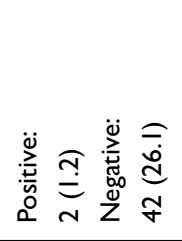 & 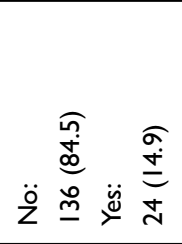 & 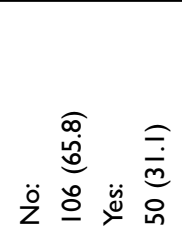 & $\begin{array}{l}\widehat{\sigma} \\
\stackrel{0}{0} \\
\sigma\end{array}$ & $\widehat{\bar{c}}$ \\
\hline 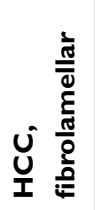 & 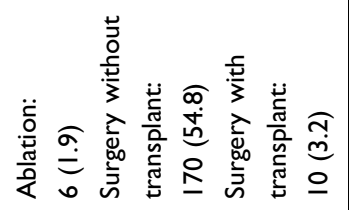 & 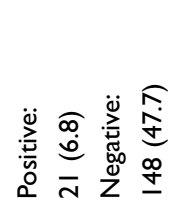 & 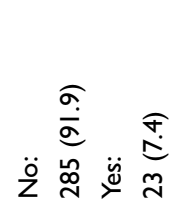 & 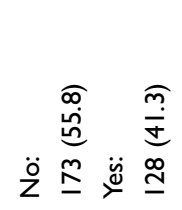 & $\begin{array}{l}\underset{\mathfrak{g}}{\mathfrak{m}} \\
\underline{m}\end{array}$ & $\frac{\widehat{\bar{\infty}}}{\stackrel{n}{n}}$ \\
\hline 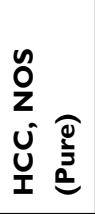 & 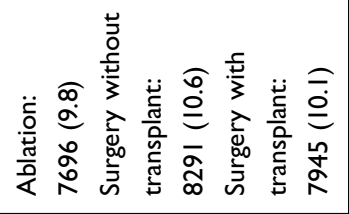 & 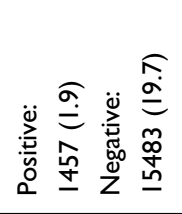 & 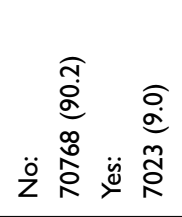 & 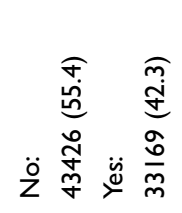 & 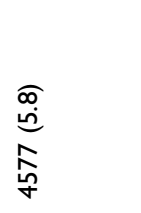 & 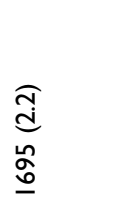 \\
\hline & 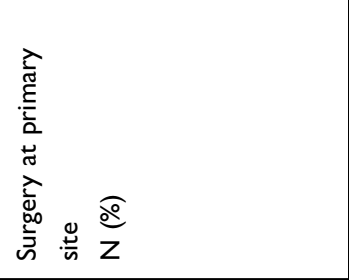 & 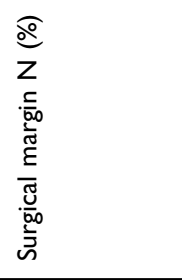 & 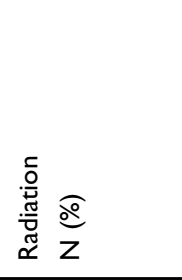 & 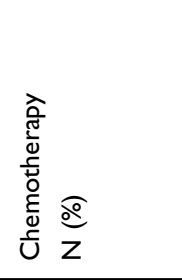 & 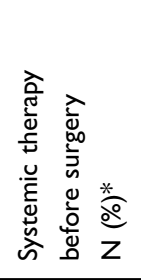 & 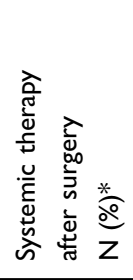 \\
\hline
\end{tabular}


Table 3 Univariate and multivariate association with overall survival (from diagnosis)

\begin{tabular}{|c|c|c|}
\hline Predictors & $\begin{array}{l}\text { Univariate Analysis } \\
\text { Hazard Ratio }(95 \% \mathrm{Cl})\end{array}$ & $\begin{array}{l}\text { Multivariate Analysis } \\
\text { Hazard Ratio }(95 \% \mathrm{Cl})\end{array}$ \\
\hline Mixed HCC & I.I3; I.04-I.23; $p=0.003$ & I.I8; I.09-I.28; $p<0.001$ \\
\hline Pleomorphic & $1.63 ; 1.07-2.51 ; p=0.025$ & $1.61 ; 1.05-2.47 ; p=0.029$ \\
\hline Clear cell & $0.92 ; 0.83-1.02 ; p=0.127$ & $1.11 ; 1.00-1.23 ; p=0.049$ \\
\hline Spindle cell & I.76; I.37-2.24; $p<0.001$ & $\mathrm{I} .3 \mathrm{I} ; \mathrm{I} .03-\mathrm{I} .68 ; p=0.030$ \\
\hline Scirrhous & $0.97 ; 0.81-1.16 ; p=0.732$ & $0.83 ; 0.69-1.00 ; p=0.045$ \\
\hline FLHCC & $0.6 \mathrm{I} ; 0.53-0.7 \mathrm{I} ; p<0.00 \mathrm{I}$ & $0.77 ; 0.66-0.89 ; p<0.001$ \\
\hline \multicolumn{3}{|l|}{ Pure HCC* } \\
\hline Female & $0.87 ; 0.86-0.89 ; p<0.001$ & $0.90 ; 0.88-0.92 ; p<0.001$ \\
\hline \multicolumn{3}{|l|}{ Male* } \\
\hline Diagnosis between 2009-2013 & $0.87 ; 0.86-0.89 ; p<0.001$ & $0.88 ; 0.86-0.90 ; p<0.001$ \\
\hline \multicolumn{3}{|l|}{ Diagnosis between 2004-2008* } \\
\hline Treatment at academic center & $0.55 ; 0.54-0.56 ; p<0.001$ & $0.77 ; 0.75-0.78 ; p<0.001$ \\
\hline \multicolumn{3}{|l|}{ Treatment at comprehensive community cancer program* } \\
\hline Well differentiated & $0.57 ; 0.55-0.59 ; p<0.001$ & $0.64 ; 0.62-0.66 ; p<0.001$ \\
\hline Moderately differentiated & $0.59 ; 0.57-0.60 ; p<0.001$ & $0.79 ; 0.76-0.82 ; p<0.001$ \\
\hline \multicolumn{3}{|l|}{ Poorly differentiated/undifferentiated* } \\
\hline Positive surgical margin & $2.60 ; 2.44-2.77 ; p<0.001$ & I.52; I.42-1.62; $p<0.001$ \\
\hline \multicolumn{3}{|l|}{ Negative surgical margin* } \\
\hline Stage I & $0.2 \mathrm{I} ; 0.20-0.2 \mathrm{I} ; p<0.00 \mathrm{I}$ & $0.32 ; 0.31-0.33 ; p<0.001$ \\
\hline Stage II & $0.25 ; 0.24-0.25 ; p<0.001$ & $0.4 I ; 0.40-0.43 ; p<0.00 I$ \\
\hline Stage III & $0.60 ; 0.59-0.62 ; p<0.001$ & $0.73 ; 0.7 I-0.75 ; p<0.00 I$ \\
\hline \multicolumn{3}{|l|}{ Stage IV* } \\
\hline Chemotherapy & $0.76 ; 0.75-0.77 ; p<0.001$ & $0.52 ; 0.5 I-0.53 ; p<0.00 I$ \\
\hline \multicolumn{3}{|l|}{ No chemotherapy* } \\
\hline Systemic therapy before surgery & $0.25 ; 0.24-0.26 ; p<0.001$ & I.43; I.35-1.52; $p<0.001$ \\
\hline \multicolumn{3}{|l|}{ No systemic therapy and/or no surgery* } \\
\hline Systemic therapy after surgery & $0.60 ; 0.57-0.64 ; p<0.001$ & $1.62 ; 1.52-1.73 ; p<0.001$ \\
\hline \multicolumn{3}{|l|}{ No systemic therapy and/or no surgery* } \\
\hline Surgery without transplant & $0.3 \mathrm{I} ; 0.30-0.32 ; p<0.00 \mathrm{I}$ & $0.25 ; 0.24-0.26 ; p<0.001$ \\
\hline \multicolumn{3}{|l|}{ No surgery* } \\
\hline Ablation & $0.40 ; 0.39-0.4 I ; p<0.001$ & $0.36 ; 0.34-0.38 ; p<0.001$ \\
\hline \multicolumn{3}{|l|}{ No surgery* } \\
\hline Surgery with transplant & $0.13 ; 0.12-0.13 ; p<0.001$ & $0.15 ; 0.14-0.15 ; p<0.001$ \\
\hline \multicolumn{3}{|l|}{ No surgery* } \\
\hline Radiation & I.09; I.06-1.12; $p<0.001$ & $0.63 ; 0.61-0.65 ; p<0.001$ \\
\hline No radiation* & & \\
\hline
\end{tabular}

Note: *Reference

$p<0.001$ ), female sex (HR 0.90; 0.88-0.92; $p<0.001$ ), diagnosis between 2009 and 2013 (HR 0.88; 0.86-0.90, $p<0.001$ ), treatment at academic center (HR $0.77 ; 0.75$ $0.78 ; p<0.001)$, well $/$ moderately differentiated histology (HR 0.64; $0.62-0.66 ; p<0.001$ and HR $0.79 ; 0.76-0.82$; $p<0.001$ ), chemotherapy (HR 0.52; 0.51-0.53; $p<0.001$ ), surgery with liver transplant (HR $0.14 \quad(0.14-0.15$, $p<0.001$ ) and surgery without liver transplant (HR 0.25 ; $0.24-0.26 ; p<0.001)$ were associated with better OS compared to pure HCC, male sex, diagnosis between 2004 and 
Table 4 Multivariate survival analysis of OS by chemotherapy* - stratified by histology

\begin{tabular}{|l|l|l|l|}
\hline Covariate & Level & Hazard Ratio (95\% Cl) & HR $p$-value \\
\hline Comparisons stratified by histology: & Chemotherapy: & REF: No & - \\
\hline Combined HCC and cholangio (Mixed HCC) & Yes vs No & $0.59(0.49-0.69)$ & $<0.00 I$ \\
HCC, pleomorphic type & Yes vs No & $0.71(0.29-1.77)$ & 0.464 \\
HCC, clear cell type & Yes vs No & $0.52(0.42-0.64)$ & $<0.00 I$ \\
HCC, spindle cell variant & Yes vs No & $0.58(0.34-0.99)$ & 0.046 \\
HCC, scirrhous & Yes vs No & $0.75(0.5 I-1.12)$ & 0.161 \\
HCC, fibrolamellar & Yes vs No & $0.65(0.48-0.87)$ & 0.004 \\
HCC, NOS(Pure) & Yes vs No & $0.52(0.5 I-0.53)$ & $<0.00 I$ \\
\hline
\end{tabular}

Notes: *Chemotherapy (NAACCR Item \#1390). Prior to 2013, targeted therapies that invoke an immune response, such as Herceptin, had been coded as chemotherapy. Effective with cases diagnosed January I, 2013, and forward these therapies are classified as biological response modifiers. Coding instructions for these changes have been added to the remarks field for the applicable drugs in the SEER*RX Interactive Drug Database (http://seer.cancer.gov/tools/seerrx/).

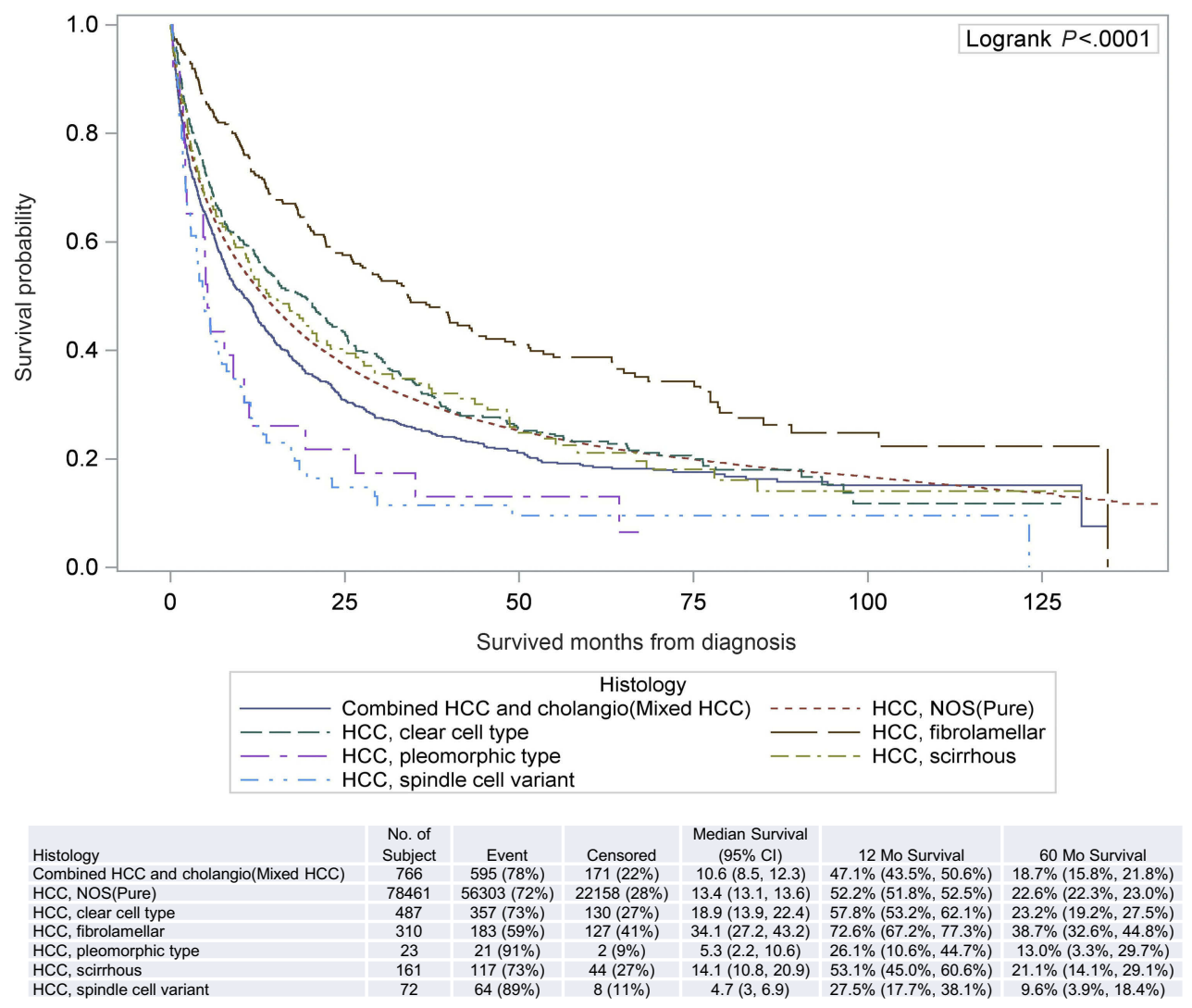

Figure 2 Survival curves by histology.

2008 , treatment at comprehensive community cancer program, poorly differentiated, late stage, no chemotherapy, and no surgery $(p<0.001)$. The survival differences above were also significant in univariate analysis.

\section{Discussion}

According to the American Cancer Society, 42,220 new cases of liver cancer was estimated to be diagnosed in the US during $2018 .{ }^{22} \mathrm{HCC}$ incidence has been rising over the past two decades. In this NCDB analysis, a higher number of patients were diagnosed between 2009 and 2013 as compared to 2004 and 2008. HCC variants have unique clinical presentations, treatment strategies and outcomes when compared to pure HCC.

FLHCC is the most common HCC variant ${ }^{18,23}$ reported in literature and it was the second most common $\mathrm{HCC}$ variant after mixed type $\mathrm{HCC}$ in this study. In this study patients with FLHCC were younger and presented with more advanced stage at diagnosis, similar to prior studies. ${ }^{5,18,24}$ In FLHCC, gender distribution in this study showed more male patients 
which differs from previous reports. ${ }^{5,15}$ The 5 -year survival for FLHCC was significantly better than pure HCC.

The scirrhous subtype is poorly studied. In this study, these patients presented with earlier stage and were more likely to undergo surgical resection with liver transplant compared to surgical resection without transplant or ablation; similar to the results obtained in a previous study. ${ }^{5}$ Reported OS varies significantly, ${ }^{25,26}$ but this study demonstrated that OS of scirrhous subtype was similar to pure HCC.

Clear cell HCC is poorly studied and there is no current consensus regarding the effect of clear cell features on prognosis. In this study, most of the clear cell HCC patients presented with early-stage disease, and were found to have a similar overall survival to pure HCC. Pleomorphic subtype is probably the least understood variant of HCC. Pleomorphic HCC often presents with latestage disease and has significantly lower OS compared to pure HCC, which was evident in this study as more than $60 \%$ presented with stage III or IV disease.

Spindle subtype has been characterized in a few small studies and it is highly aggressive. ${ }^{27}$ Findings in this study revealed that spindle cell subtype presents more frequently with late-stage disease and has the shortest median overall survival rate (4.7\%). Mixed type HCC has high recurrence rates and poor prognosis. ${ }^{28,29}$ In this analysis, the majority of mixed type HCC presented with late-stage disease and had poorer OS compared to pure HCC. There was a relatively high rate of surgery with transplant for the management of mixed type HCC in this study.

Liver transplant, surgical resection, and ablative procedures were associated with significantly better overall survival as compared to no surgery for pure HCC and HCC variants. Surgical interventions were more likely in $\mathrm{HCC}$ variants as compared to pure HCC. More than half of the FLHCC patients underwent surgical resection without transplant which was significantly higher compared to pure HCC. Although $61 \%$ of FLHCC patients presented with stage III and IV disease they underwent surgery without transplantation more often which may be related to the younger age, indolent growth, favorable biological behavior, absence of chronic liver disease, and suitability to extensive liver resection. ${ }^{30-34}$ Liver transplantation is an effective treatment for pure HCC. ${ }^{16}$ Although not an established treatment modality for $\mathrm{HCC}$ variants, a considerable percentage of patients with $\mathrm{HCC}$ variants underwent liver transplantation. Orthotopic liver transplantation has been employed in FLHCC. ${ }^{16,30,35-37}$ FLHCC which is not amenable to resection but confined to the liver is considered a suitable indication for liver transplantation by the majority of investigators.

Jernigan et al studied 784 patients with HCC variants (fibrolamellar, scirrhous, spindle cell, clear cell, mixed type, and trabecular) from NCDB between 1998 and 2011. ${ }^{5}$ Only the patients who underwent surgical management with resection, transplantation or local ablation were included. Adjuvant therapy data was provided but no data was included about neoadjuvant chemotherapy or radiotherapy. No pleomorphic histology was identified and patients with pure HCC were not included in the study. Survival data for patients after 2006 was not included in the same study. Systemic therapy [defined as "Chemotherapy (NAACCR Item \#1390), Hormone Therapy (NAACCR Item \#1300), Immunotherapy (NAACCR Item \#1410) and Hematologic Transplant and Endocrine Procedure (NAACCR Item \#3250)"] for advanced HCC was not established prior to 2007 until sorafenib became the first FDA approved systemic therapy option for advanced HCC based on SHARP trial. ${ }^{8}$ The current study included patients with pure HCC and HCC variants not only surgically managed but also medically managed in contrast to the study by Jernigan et al.

In this study, chemotherapy [Chemotherapy (NAACCR Item \#1390) including targeted therapy] was administered in almost half of the patients. Chemotherapy administration ranged between $31.1 \%$ and $41.3 \%$ among $\mathrm{HCC}$ variants indicating regular use of chemotherapy in these entities in regular clinical practice despite absence of clinical trial data. The role of chemotherapy in the pre or post-operative setting in pure HCC and HCC variants is controversial. The study conducted by Jernigan et al concluded that adjuvant therapy did not significantly change mortality, ${ }^{5}$ however, in the study by Wang et al adjuvant treatments prolonged survival. ${ }^{38}$ In this study, pre or post-operative use of chemotherapy was more common in HCC variants as compared to pure HCC. Furthermore, chemotherapy was associated with improved OS in all histologies except for scirrhous and pleomorphic HCC.

The limitations to this study include retrospective design, absence of detailed information on the chemotherapy regimens, and lack of data related to liver directed therapy in the NCDB. The Child Pugh class and score, Barcelona clinic liver cancer (BCLC) staging, vascular invasion status, hepatitis status, location of extra-hepatic metastasis could not be determined due to the nature of the NCDB database. In addition, disease-specific mortality, recurrence indices, response to treatment and prior history of malignancies are not captured in the NCDB. ${ }^{39}$ Several 
of the HCC variants have only been recognized and included in the NCDB in more recent years, ${ }^{5}$ and variant histologies are not limited to the ones included in this study. Furthermore, accurate pathologic classification of HCC variants could be a challenge especially at centers that may not have dedicated gastrointestinal pathologists. This analysis is based on the diagnosis codes utilized for each specific HCC type, histological diagnosis may have not been available in all cases of HCC. Despite these limitations, this study is the largest collective series currently available for the six HCC variants in the United States and provides a contemporary analysis of treatment patterns and clinical outcomes. It could provide guidance for treatment decisions for these rare entities.

\section{Conclusion}

The HCC variants differ in clinical presentation, most frequently utilized treatment modalities and clinical outcomes. FLHCC had the best 5-year overall survival. HCC variants underwent surgical resection more often than HCC. Liver transplant is commonly performed in HCC variants.

\section{Acknowledgments}

Part of data presented in this study was presented at the 2019 Gastrointestinal Cancers Symposium in San Francisco, CA. The manuscript's abstract was published in "Abstracts" in Journal of Clinical Oncology: DOI: 10.1200/JCO.2019.37.4_suppl.435 and Journal of Clinical Oncology 37, no. 4_suppl (February 1 2019) 435-435. Research reported in this publication was supported in part by the Winship Research Informatics Shared Resource of Winship Cancer Institute of Emory University and NIH/NCI under award number P30CA138292. The data used in the study are derived from a de-identified NCDB file. The NCDB is a joint project of the Commission on Cancer of the American College of Surgeons and the American Cancer Society. The American College of Surgeons and the Commission on Cancer have not verified and are not responsible for the analytic or statistical methodology employed, or the conclusions drawn from these data by the investigator.

\section{Author contributions}

All authors contributed to data analysis, drafting or revising the article, gave final approval of the version to be published, and agree to be accountable for all aspects of the work.

\section{Disclosure}

The authors report no conflicts of interest in this work.

\section{References}

1. Organization, W. H. Cancer; 2018. Available from: http://www.who. int/news-room/fact-sheets/detail/cancer. Accessed June 29, 2019

2. Siegel RL, Miller KD, Jemal A. Cancer statistics, 2018. CA Cancer J Clin. 2018;68:7-30. doi:10.3322/caac.21442

3. Altekruse SF, Henley SJ, Cucinelli JE, McGlynn KA. Changing hepatocellular carcinoma incidence and liver cancer mortality rates in the United States. Am J Gastroenterol. 2014;109:542-553. doi:10.1038/ajg.2014.11

4. Khalaf N, Ying J, Mittal S, et al. Natural history of untreated hepatocellular carcinoma in a US cohort and the role of cancer surveillance. Clin Gastroenterol Hepatol. 2017;15:273-281.e271. doi:10.1016/j.cgh.2016.07.033

5. Jernigan PL, Wima K, Hanseman DJ, et al. Natural history and treatment trends in hepatocellular carcinoma subtypes: insights from a national cancer registry. $J$ Surg Oncol. 2015;112:872-876. doi:10.1002/jso. 24083

6. Forner A, Llovet JM, Bruix J. Hepatocellular carcinoma. Lancet (London, England). 2012;379:1245-1255. doi:10.1016/s0140-6736 (11)61347-0

7. Lesurtel M, Clavien PA. 2010 international consensus conference on liver transplantation for hepatocellular carcinoma: texts of experts. Liver Transpl. 2011;17(Suppl 2):S1-S5. doi:10.1002/1t.22350

8. Llovet JM, Link E, Parish S, et al. Sorafenib in advanced hepatocellular carcinoma. N Engl J Med. 2008;359:378-390. doi:10.1056/ NEJMoa0708857

9. Kudo, M., Finn RS, Qin S, et al. Lenvatinib versus sorafenib in firstline treatment of patients with unresectable hepatocellular carcinoma: a randomised phase 3 non-inferiority trial. Lancet (London, England). 2018;391:1163-1173. doi:10.1016/s0140-6736(18)30207-1

10. Bruix J, Qin S, Merle P, et al. Regorafenib for patients with hepatocellular carcinoma who progressed on sorafenib treatment (RESORCE): a randomised, double-blind, placebo-controlled, phase 3 trial. Lancet (London, England). 2017;389:56-66. doi:10.1016/ s0140-6736(16)32453-9

11. El-Khoueiry AB, Sangro B, Yau T, et al. Nivolumab in patients with advanced hepatocellular carcinoma (CheckMate 040): an open-label, non-comparative, phase $1 / 2$ dose escalation and expansion trial. Lancet (London, England). 2017;389:2492-2502. doi:10.1016/ s0140-6736(17)31046-2

12. Abou-Alfa GK, Meyer T, Cheng AL, et al. Cabozantinib in patients with advanced and progressing hepatocellular carcinoma. $N$ Engl $J$ Med. 2018;379:54-63. doi:10.1056/NEJMoa1717002

13. Zhu, AX, Finn RS, Edeline J, et al. Pembrolizumab in patients with advanced hepatocellular carcinoma previously treated with sorafenib (KEYNOTE-224): a non-randomised, open-label phase 2 trial. Lancet Oncol. 2018;19:940-952. doi:10.1016/s1470-2045(18)30351-6

14. El-Serag HB, Davila JA. Is fibrolamellar carcinoma different from hepatocellular carcinoma? A US population-based study. Hepatology. 2004;39(3):798-803. doi:10.1002/hep.20096

15. Stipa, F., Yoon SS, Liau KH, et al. Outcome of patients with fibrolamellar hepatocellular carcinoma. Cancer. 2006;106:1331-1338. doi:10.1002/cner.21703

16. Kassahun WT. Contemporary management of fibrolamellar hepatocellular carcinoma: diagnosis, treatment, outcome, prognostic factors, and recent developments. World J Surg Oncol. 2016;14(151). doi:10.1186/s12957-016-0903-8

17. Ang CS, Kelley RK, Choti MA, et al. Clinicopathologic characteristics and survival outcomes of patients with fibrolamellar carcinoma: data from the fibrolamellar carcinoma consortium. Gastrointest Cancer Res. 2013;6:3-9. 
18. Mayo SC, Mavros MN, Nathan H, et al. Treatment and prognosis of patients with fibrolamellar hepatocellular carcinoma: a national perspective. J Am Coll Surg. 2014;218:196-205. doi:10.1016/j. jamcollsurg.2013.10.011

19. Kim YJ, Rhee H, Yoo JE, et al. Tumour epithelial and stromal characteristics of hepatocellular carcinomas with abundant fibrous stroma: fibrolamellar versus scirrhous hepatocellular carcinoma. Histopathology. 2017;71:217-226. doi:10.1111/his.13219

20. Sakhuja, P., Mishra PK, Rajesh R, et al. Clear cell hepatocellular carcinoma: back to the basics for diagnosis. $J$ Cancer Res Ther. 2015;11(656). doi:10.4103/0973-1482.136041

21. Liu Y, Nickleach D, Zhang C, Switchenko J, Kowalski J. Carry out streamlined routine data analyses with reports for observational studies: introduction to a series of generic SAS ® Macros. Version 2. F1000Res. 2018;7:1955. doi:10.12688/f1000research.16866.2

22. Siegel RL, Miller KD, Jemal A. Cancer statistics, 2018. CA Cancer J Clin. 2018;68(1):7-30. doi: doi:10.3322/caac.21442

23. Craig JR, Peters RL, Edmondson HA, Omata M. Fibrolamellar carcinoma of the liver: a tumor of adolescents and young adults with distinctive clinico-pathologic features. Cancer. 1980;46:372-379. doi:10.1002/1097-0142(19800715)46:2<372::aidcncr2820460227>3.0.co;2-s

24. Eggert T, McGlynn KA, Duffy A, Manns MP, Greten TF, Altekruse SF. Fibrolamellar hepatocellular carcinoma in the USA, 2000-2010: a detailed report on frequency, treatment and outcome based on the surveillance, epidemiology, and end results database. United European Gastroenterol J. 2013;1:351-357. doi:10.1177/20506 40613501507

25. Sugiki T, Yamamoto M, Taka K, Nakano M. Specific characteristics of scirrhous hepatocellular carcinoma. Hepato-gastroenterology. 2009;56: 1086-1089.

26. Lee JH, Choi MS, Gwak GY, et al. Clinicopathologic characteristics and long-term prognosis of scirrhous hepatocellular carcinoma. Dig Dis Sci. 2012;57:1698-1707. doi:10.1007/s10620-012-2075-x

27. Maeda T, Adachi E, Kajiyama K, Takenaka K, Sugimachi K, Tsuneyoshi M. Spindle cell hepatocellular carcinoma. A clinicopathologic and immunohistochemical analysis of 15 cases. Cancer. 1996;77:51-57. doi:10.1002/(sici)1097-0142(19960101)77:1<51::Aidcncr $10>3.0 . \mathrm{Co} ; 2-7$
28. Sapisochin G, Fidelman N, Roberts JP, Yao FY. Mixed hepatocellular cholangiocarcinoma and intrahepatic cholangiocarcinoma in patients undergoing transplantation for hepatocellular carcinoma. Liver Transpl. 2011;17:934-942. doi:10.1002/1t.22307

29. Jarnagin WR, Weber S, Tickoo SK, et al. Combined hepatocellular and cholangiocarcinoma: demographic, clinical, and prognostic factors. Cancer. 2002;94:2040-2046. doi:10.1002/cncr.10392

30. Ringe B, Wittekind C, Weimann A, Tusch G, Pichlmayr R. Results of hepatic resection and transplantation for fibrolamellar carcinoma. Surg Gynecol Obstet. 1992;175:299-305.

31. Pinna AD, Iwatsuki S, Lee RG, et al. Treatment of fibrolamellar hepatoma with subtotal hepatectomy or transplantation. Hepatology. 1997;26:877-883. doi:10.1002/hep.510260412

32. Kaseb AO, Shama M, Sahin IH, et al. Prognostic indicators and treatment outcome in 94 cases of fibrolamellar hepatocellular carcinoma. Oncology. 2013;85:197-203. doi:10.1159/000354698

33. Mavros MN, Mayo SC, Hyder O, Pawlik TM. A systematic review: treatment and prognosis of patients with fibrolamellar hepatocellular carcinoma. J Am Coll Surg. 2012;215(6):820-830. doi:10.1016/j. jamcollsurg.2012.08.001

34. Wood WJ, Rawlings M, Evans H, Lim CN. Hepatocellular carcinoma: importance of histologic classification as a prognostic factor Am J Surg. 1988;155:663-666. doi:10.1016/s0002-9610(88)80139-9

35. Edmondson HA. Differential diagnosis of tumors and tumor-like lesions of liver in infancy and childhood. AMA $J$ Dis Child. 1956;91:168-186.

36. El-Gazzaz G, Wong W, El-Hadary MK, et al. Outcome of liver resection and transplantation for fibrolamellar hepatocellular carcinoma. Transpl Int. 2000;13(Suppl 1):S406-S409.

37. Schlitt HJ, Neipp M, Weimann A, et al. Recurrence patterns of hepatocellular and fibrolamellar carcinoma after liver transplantation. J Clin Oncol. 1999;17:324-331. doi:10.1200/jco.1999.17.1.324

38. Wang Z, Zhang G, Wu J, Jia M. Adjuvant therapy for hepatocellular carcinoma: current situation and prospect. Drug Discov Ther. 2013;7:137-143.

39. Lee DY, Teng A, Pedersen RC, et al. Racial and socioeconomic treatment disparities in adolescents and young adults with stage IIIII rectal cancer. Ann Surg Oncol. 2017;24:311-318. doi:10.1245/ s10434-016-5626-0

\section{Publish your work in this journal}

The Journal of Hepatocellular Carcinoma is an international, peerreviewed, open access journal that offers a platform for the dissemination and study of clinical, translational and basic research findings in this rapidly developing field. Development in areas including, but not limited to, epidemiology, vaccination, hepatitis therapy, pathology and molecular tumor classification and prognostication are all considered for publication. The manuscript management system is completely online and includes a very quick and fair peer-review system, which is all easy to use. Visit http://www.dovepress.com/ testimonials.php to read real quotes from published authors. 